\title{
Ciência cidadã na promoção da biodiversidade
}

\section{Citizen Science in promoting biodiversity}

CA. Ribeiro, F. Carvalho e N. Silva. Laboratório da Paisagem de Guimarães (Portugal)

\begin{abstract}
Resumo
A ciência cidadã é hoje, reconhecidamente, uma das formas emergentes de aproximação da ciência aos cidadãos, mostrando a sua capacidade de contribuir para uma ciência mais participativa e o envolvimento destes nas diversas atividades desenvolvidas, nomeadamente aquelas que se debruçam sobre a educação para a sustentabilidade. Em causa não está apenas o potencial da ciência cidadã como estratégia para uma ação mais participada dos cidadãos, mas, essencialmente, o seu potencial de comprometimento e envolvimento destes nos principais desafios da sociedade atual. A preservação e promoção da biodiversidade é um dos exemplos aqui vertidos e cuja ligação entre aqueles que fazem ciências e os cidadãos é essencial para o cumprimento dos objetivos propostos. No presente caso, apresentam-se como exemplos a criação de uma base de dados de biodiversidade suportado pelo conceito da ciência cidadã e promotor da biodiversidade urbana e um projeto de redução e valorização de resíduos, impulsionador da redução de acumulação de resíduos nas cidades, desenvolvidos pelo Laboratório da Paisgaem de Guimarães. A ciência cidadã pode, por isso, ser uma ferramenta essencial na capacidade que demonstra de envolvimento dos cidadãos comuns, podendo e devendo ser utilizada como um instrumento de motivação da comunidade escolar para o seu envolvimento e responsabilização nomeadamente na proteção e promoção da biodiversidade.
\end{abstract}

\section{Astract}

Citizen's science is one of the emerging ways of bringing science closer to citizens, showing its capacity to contribute to a more participatory science and its involvement in several activities developed, namely those that focus on education for sustainability. Citizen's science has a great potential for the citizen's engagement and commitment in the main challenges of society. The preservation and promotion of biodiversity is one of the examples which the link between those who make science and the citizens is essential for the achievement of the proposed goals. The creation of a database of biodiversity supported by the concept of citizen science and promoter of urban biodiversity and a project for waste's reduction and recovery, contributing to the reduction of waste accumulation in cities, are the two examples proposed by the Landscape Laboratory and reported here. Citizen's science can, therefore, be an essential tool for the engagement of ordinary citizens. It also should be used as a motivating tool for the school community involving them in the protection and promotion of biodiversity.

\section{Palavras chave}

Ambiente; Biodiversidade; Ciência-Cidadã; educação; sustentabilidade.

\section{Key-words}

Biodiversity; Citizen Science; education; environment; sustainability. 


\section{Ciência-Cidadã e Biodiversidade}

Como definição, a biodiversidade corresponde à variedade de ecossistemas, espécies e genes que nos rodeia (União Europeia). Esta biodiversidade apesar de valer por si só proporciona à sociedade uma vasta gama de serviços ecossistémicos dos quais dependemos, como os alimentos, a água doce, a polinização, a proteção contra as inundações, etc. Apesar de ser inquestionável o valor da biodiversidade e das funções e serviços que a mesma proporciona, verifica-se que a nível global a ameaça à biodiversidade é hoje incontornável, com as espécies a desaparecem a um nível muito elevado fruto, essencialmente, de ações humanas que põe em causa a sustentabilidade da vida no planeta. Assim, preocupada com o rumo da biodiversidade na Europa, em maio de 2011, a Comissão Europeia adotou uma nova estratégia que estabelece o quadro de ação da UE para os dez anos seguintes com vista a atingir o objetivo central para 2020 em matéria de biodiversidade.

Reconhece-se, porém, que o sucesso das metas traçadas só será alcançado se existir uma mudança nos paradigmas atuais, com foco no crescimento do trabalho científico no que toca à conservação e preservação da biodiversidade, mas também no envolvimento da sociedade em geral, nas preocupações, no trabalho de campo e na execução das metas estabelecidas. Durante séculos as pessoas registaram as suas observações do mundo natural, incluindo fenologias e distribuições de plantas e animais, qualidade da água, dados sobre a meteorologia e fenómenos astronómicos (Dıckinson, 2012). Crê-se que a renovação do interesse na ciência cidadã, uma indispensável forma de combinar, enriquecida com a perspetiva e os dados provenientes de uma longa tradição na participação pública na ciência irá alargar a ligação e o compromisso do público na investigação em ecologia e levar a novas descobertas científicas. As aproximações à ciência cidadã variam desde monitorizações feitas pela comunidade, o uso da internet para variadas tarefas científicas em formato "crowd-source", partilha de informação e dados entre comunidades, até à recolha de dados para descobertas. A ciência do cidadão e os dados ecológicos resultantes podem ser visto como um bem público que é produzido através do aumento de ferramentas de colaboração e recursos, promovendo ao mesmo tempo a participação do público na ciência e na preservação do planeta.

Nesse sentido, o Laboratório da Paisagem de Guimarães em estreita colaboração com o Município de Guimarães e no âmbito mais alargado de um plano estratégico de desenvolvimento sustentável do território -Guimarães mais Verde- e impulsionador da Candidatura de Guimarães a Capital Verde Europeia procurou, suportado 
pelo conceito de ciência-cidadã, desenvolver projetos que visassem a preservação e promoção da biodiversidade, procurando envolver os cidadãos nos principais desafios do território.

\section{Laboratório da Paisagem como Promotor de Educação Ambiental}

O Laboratório da Paisagem enquanto centro de investigação, procura desenvolver diversos projetos de investigação, integrando-os num contexto de educação ambiental e de envolvimento da comunidade, nomeadamente a comunidade escolar. Neste sentido, o Laboratório da Paisagem atua numa base multidisciplinar procurando num conceito inovador, aglutinar à experiência de gestão do território do poder local, o conhecimento fornecido pelas universidades - a Universidade do Minho e a Universidade de Trás-os-Montes e Alto Douro.

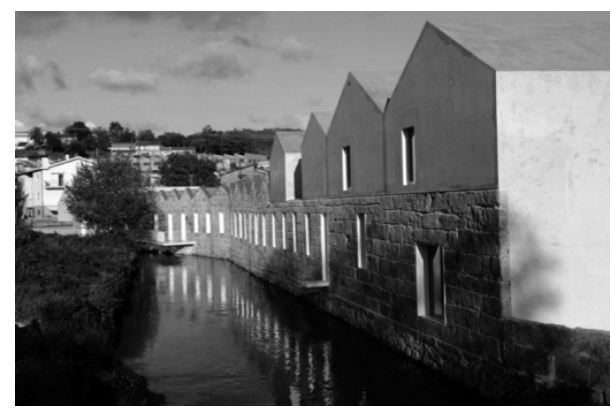

Figura 1: Laboratório da Paisagem de Guimarães
Reconhecendo a importância da Ciência-Cidadã, acima descrita, o Laboratório da Paisagem de Guimarães é ainda membro da Associação Europeia de Ciência-Cidadã, procurando através desta contribuir para o fortalecimento de estratégias indutoras da participação da sociedade nos principais desafios ambientais atuais.

\section{Biodiversity GO! Base de Dados de Biodiversidade}

Dado o relativo crescimento da investigação em ecologia como campo de estudo profissional, as contribuições históricas de "amadores" para a ecologia podem facilmente ser subestimadas. De forma a perceber alterações a longo prazo nos ecossistemas, os investigadores estão agora a revisitar muitas destas base-de-dados históricas criadas com registos de pessoas não profissionais deste campo de estudo. Ao longo dos últimos 100 anos as organizações científicas foram aumentando a inclusão de voluntários em projetos de monitorização de larga-escala para aumentar a extensão geográfica e o tamanho da amostragem relativamente às observações (Miller-Rushing, 2012).

Desta forma, e face à inexistência de uma base de dados de toda a biodiversidade do concelho, o Laboratório da Paisagem procurou desenvolver um projeto que vi- 
sasse a sua criação suportada pelo conceito de ciência-cidadã, possibilitando assim que o projeto pudesse ser uma ferramenta útil para ser utilizada em contexto escolar. O desenvolvimento de uma aplicação móvel para utilização em qualquer smartphone procurou também responder ao uso massivo destes e potenciar ainda o envolvimento da população mais jovem neste projeto. Assim, o projeto passou igualmente a ser uma das atividades principais do programa ambiental municipal PEGADAS, resultando em centenas de contributos que permitem servir de base para a avaliação do potencial florístico e faunístico dos vários espaços verdes do concelho.

A partir desses contributos, será ainda possível criar bases informativas para residentes e visitantes e, paralelamente, estudar a evolução da biodiversidade num contexto científico, podendo servir de base ao desenvolvimento de projetos nesta área.

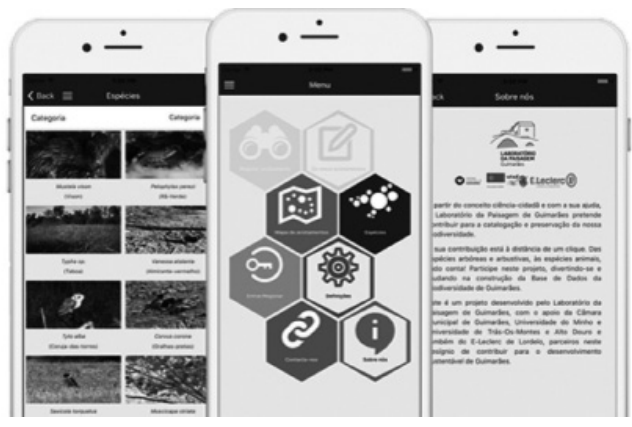

Figura 2: Aplicação móvel Biodiversity GO! Que visa a criação de uma base de dados de biodiversidade

\section{EcoPontas \& PapaChicletes. Redução e Valorização de Resíduos}

O aumento gradual da produção de resíduos sólidos urbanos, por força da expansão e urbanização das cidades tem sido um dos principais problemas com que se debatem todas as cidades. Para este facto, e principalmente para os resíduos acumulados nas ruas das cidades muito tem contribuído aquele que é designado por micro-lixo e para o qual as pontas de cigarro e pastilhas elásticos contribuem de forma decisiva. Um pouco por todo o mundo, são mesmo dos resíduos mais encontrados, compreendendo em muitos casos cerca de $70 \%$ dos resíduos identificados (Hosford, 2016). As pontas de cigarro são igualmente os resíduos mais recolhidos nas praias em todo o mundo (Ocean Conservancy International Coastal Cleanup, 2007), sendo que o impacto da acumulação destes resíduos nos ecossistemas aquáticos tem sido amplamente descrito, nomeadamente no que concerne à presença de determinadas toxinas, nicotina e outros agentes cancerígenos assim como a presença do filtro constituído por plástico não biodegradável (Elli SLAUGHTER, 2011).

Reconhece-se que o sucesso dos projetos está intimamente ligado com a sua capacidade de envolvimento da população e, 


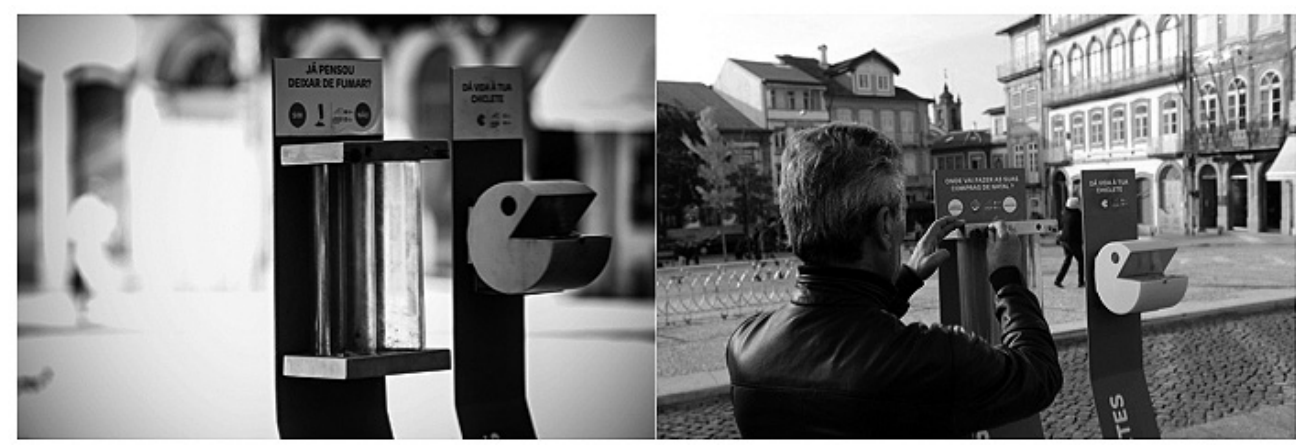

Figura 3: EcoPontas e PapaChicletes - Novas estruturas de mobiliário urbano para redução de acumulação de resíduos de pontas de cigarro e pastilhas elásticas

mais do que isso, de promoção da educação e sensibilização ambiental. Desta forma, e no sentido de contribuir para o envolvimento da população, procurou-se através de mecanismos de participação ativa nomeadamente em contexto escolar que os vídeos promocionais lançados na apresentação oficial do projeto foram realizados em parceria com uma escola secundária do concelho, cumprindo assim o propósito de alertar os alunos e toda a comunidade escolar para as consequências associadas à acumulação de resíduos de pontas de cigarro e pastilhas elásticas. Do mesmo modo, a estreita ligação com as escolas permitiu recolher o feedback dos estudantes durante o processo de desenvolvimento de alguns pormenores das referidas estruturas.

\section{Conclusão}

Mais do que um chavão, o conceito de ciência-cidadã será cada vez mais fulcral na ligação da sociedade aos principais desafios ambientais da humanidade. Envolver e comprometer, deverão ser palavras de ordem para, cada vez mais, serem procuradas soluções que visem motivar a população para responder aos objetivos de proteção e promoção do património natural.

\section{Referências bibliográficas}

DICKINSON (2012). The current state of citizen science as a tool for ecological research and public engagement. Frontiers in Ecology and the Environment, 10(6), 291-297.

MILLER-RUSHING (2012). The history of public participation in ecological research. Frontiers in Ecology and the Environment, 10(6), 285-290.

HOSFORD (2016). Cigarettes and chewing gum are still the biggest litter problems in Ireland. The Journal, 1.

ELLI SLAUGHTER (2011). Toxicity of cigarette butts, and their chemical components, to marine and freshwater fish. California: group.bmj. com. 